\title{
IoT Smart Home Lighting System using Arduino UNO and ESP8266
}

\author{
Edwin Nair Jannatheran, Vincent Yong Kai Loung, Graduate Student Member, IEEE, Chee Yen Leow, Member, \\ IEEE
}

\begin{abstract}
Today, a wide variety of IoT applications and services have appeared and one of them is the Smart Home. The objective of this article is to present basic electrical wiring using Arduino UNO board and ESP8266, writing in C programming Language in Arduino software Integrated Development Environment (IDE) to develop and build a prototype Smart Home Lighting System that displays the lighting of two fluorescent lamps when the switch button was turned on by the user from ESP8266 Web Server. The system installation has a real-time synchronization that is necessary and safe for immersive IoT applications.
\end{abstract}

Index Terms - Arduino UNO, ESP8266, Internet of Things, Smart Home, Wi-Fi

\section{INTRODUCTION}

OMMUNICATION services such as the Internet of Things (IoT) have emerged via the initiative of Industrial Revolution 4.0 (IR 4.0). The Internet of things (IoT) is the network comprising of wireless devices that contain sensors, actuators, and software that enables connectivity between humans and machines to interact and exchange data [1]. The blooming technology is vastly used in various domains interconnecting physical approaches through the Internet [2]. The Smart Home has become a well-known technology and the necessity of remotely controlling our home appliances which had increased over the year and adequate software applications had been developed to achieve different services [3].

The use cases of IoT are mainly for automation purposes in industries covering aerospace, manufacturing, transportation, and energy sectors to harness effective operation and production remotely. This article aims to design and propose a Smart Home system installation using Arduino and ESP8266 which turns on the lighting system. The various devices that can be supported for IoT had been delivered in [4] together with common resources and different sensing parameters.

The IoTs enable us to automate home applications and carry out industrial tasks such as controlling more and more wireless devices in our home or work environment and sharing information with other users, wireless devices that are

Manuscript received November 29, 2021. This work was supported in part by the Malaysian Government under the Penjana Scheme Human Resources Development Fund - Gerak Ihsan Gemilang (HRDF - GIG) for conducting this successful training program at CQ-TEC (P. J.) SDN BHD during the COVID19 pandemic.

Edwin Nair Jannatheran and Vincent Yong Kai Loung have successfully worked together, and completed the training scheme by Human Resources Development Fund initiative. dynamically interconnected [5]. Smartphones are the most common wireless devices that can be able to maintain network connectivity wirelessly through wireless medium to the enduser, in the enterprises, industrial and remote location. There are two wireless communication standards namely short-range and long-range communication standards. Examples of shortrange communication technologies empowering the IoTs are Wi-Fi, Zigbee, and Bluetooth. As for the long-range communication technologies for Low Power Wide Area (LPWA) networks such as LoRa, Sigfox, and NB-IoT which can cover long distances up to 10 kilometers [6] or above with low amounts of data, and power transmission.

Telecommunication operators will be considering deploying the LPWA networks quickly for a new source of revenue because a high number of consumers will be expected for higher data rate, along with IoT devices, Artificial Intelligence (AI), as well as the latest $5 \mathrm{G}$ communication services [7] supporting future applications such as checking the soil moisture levels in smart farming, smart tracking of freight, and checking the state of the production in real-time and smart metering for electricity or gas.

The concept of a home automation system started a few years ago when IoT devices and embedded systems come into play by connecting with stationery home appliances to improve users' experience on the impact of the Internet of Things (IoT) application. The users can view and control their home environment with their touchscreen smartphone in the palm of their hands such as fluorescent lamps, fans, and air conditioning [5], connected. The success of the Smart Home system depends on the coding in $\mathrm{C}$ using Arduino, and the IoT device installation to control the lighting of two lamps by turning on the switch button, accessing from ESP8266 Web Server when connecting to the Wireless Fidelity (Wi-Fi). The proposed of our Smart Home system using both Arduino UNO and ESP8266 is developed at CQ-TEC (P. J.) SDN BHD classroom, in Malaysia to test the IoT Smart Home system capability, presented in section II.

Edwin Nair Jannatheran, Vincent Yong Kai Loung, and Chee Yen Leow are with the Wireless Communication Centre, School of Electrical Engineering, Faculty of Engineering, Universiti Teknologi Malaysia, Skudai 81310, Malaysia (e-mail: edwinnair88@gmail.com; yklvincent2@graduate.utm.my). 
$>$ REPLACE THIS LINE WITH YOUR MANUSCRIPT ID NUMBER (DOUBLE-CLICK HERE TO EDIT) <

\section{COMPONENTS}

In this section, the proposed Smart Home Lighting System components are discussed.

\section{A. Arduino UNO and IDE Installation}

Arduino is open-source electronics prototyping platform based on easy-to-use hardware and software which configure relative input to certain desired output with a simplified version of $\mathrm{C}++[8]$. The Arduino UNO is the first microcontroller board with a USB connection to a computer and it runs the program using the Arduino software Integrated Development Environment (IDE) to get started. It is free software that can be downloaded from [9]. The windows will start to install the drivers once the Arduino UNO board is connected to one of the USB ports of a computer to initiate synchronization for communication between the computer and the Arduino UNO board. The drivers' installation procedure is listed in [10]. Arduino UNO board consists of 6 analog input pins, and 14 digital input/output pins, of which 6 can be used as PWM outputs, a $16 \mathrm{MHz}$ crystal oscillator, an ICSP header, and a reset button [11] which is shown in Figure 1. In Figure 2, the Arduino UNO board is connected to the lighting system with the power supply from the battery.

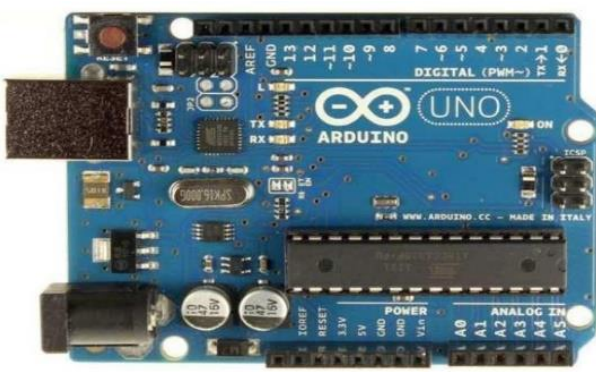

Fig. 1. Arduino UNO board.

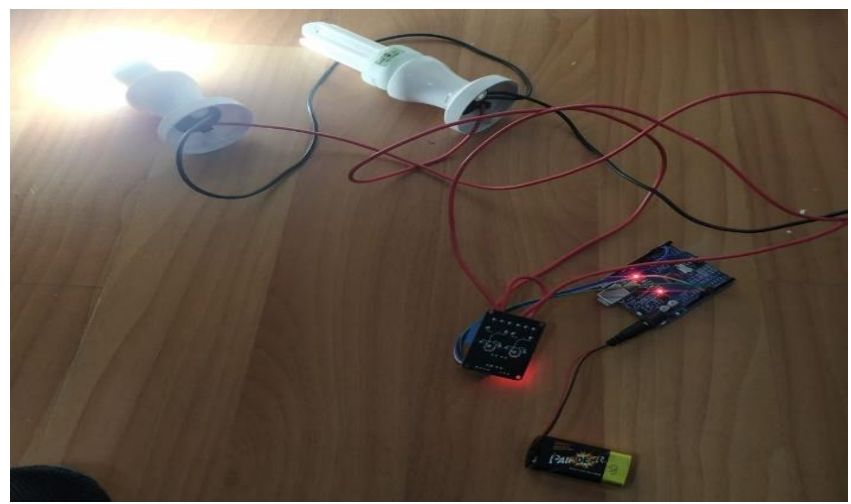

Fig. 2. Arduino UNO board connecting to lighting system powered by the battery.

\section{B. Electrical Wiring Installation}

The challenges faced in Malaysia are the stringent regulations and the Standard Operating Procedures (SOPs) for electrical wiring in homes and premises. The guidelines are based on the guideline of Electricity Supply Act 1990, The Electricity Regulations 1994, MS IEC 60364:2003 Standard: Electrical Installations of Buildings, MS 1936:2006 Standard: Electrical Installations of Buildings - Guide To MS IEC 60364, MS 1979:2007 Standard: Electrical Installation of Buildings - Code of Practice which are strictly prepared by the National Energy Commission under the Suruhanjaya Tenaga Malaysia (www.st,gov.my) [12]. These guidelines are prepared for all wiremen and electrical contractors to ensure safety and quality electrical wiring guide in residential buildings to conform to the Electricity Regulations 1994. Figure 3. shows how to install the lighting system using PVC conduit wiring.

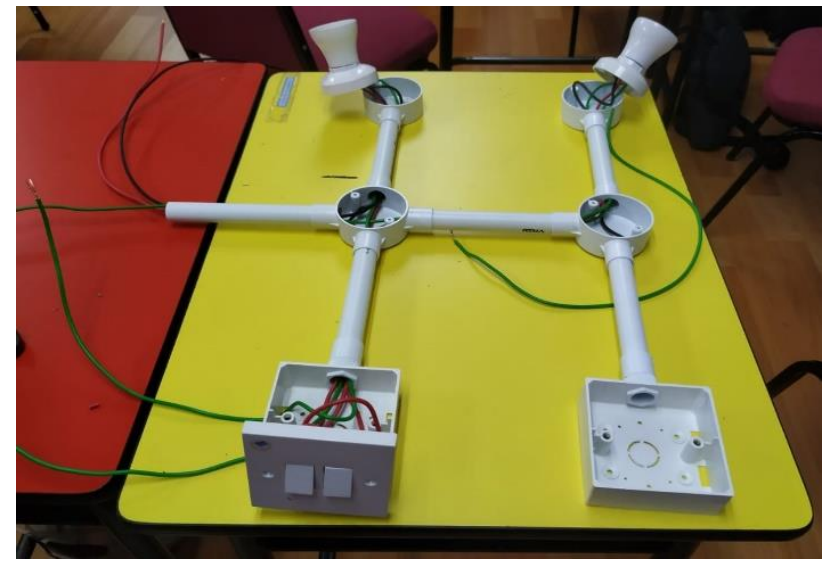

(a)

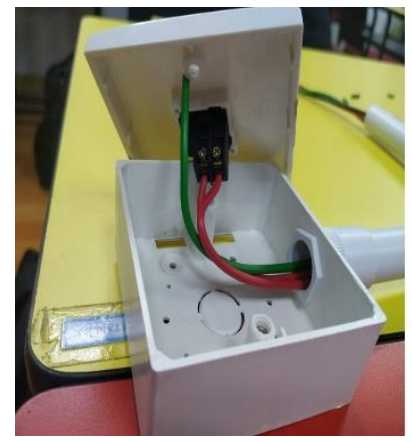

(b)

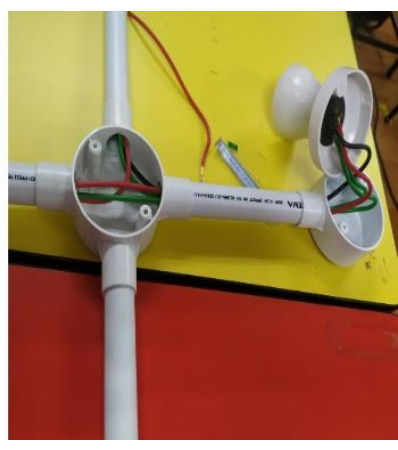

(c)
Fig. 3. (a) Basic wiring installation of the lighting system using PVC conduit. (b) Wiring installation for the switch. (c) Wiring installation for the lighting system.

\section{Distribution Box}

A Distribution Box (DB) is a power system component that splits the main electrical supply into subsidiary circuits within a home. It protects each circuit in a common enclosure within the house. The example of wiring inside the DB for the lighting of 2 fluorescent lamps with switches for a single phase is shown in Figure 4. Live wire is red, Neutral is black, and green is for Earth. 


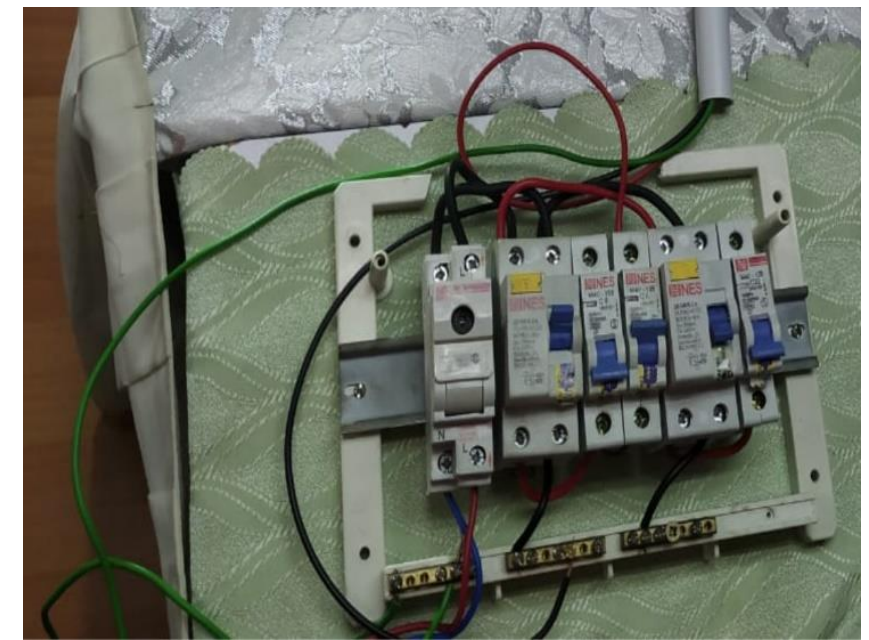

(a)

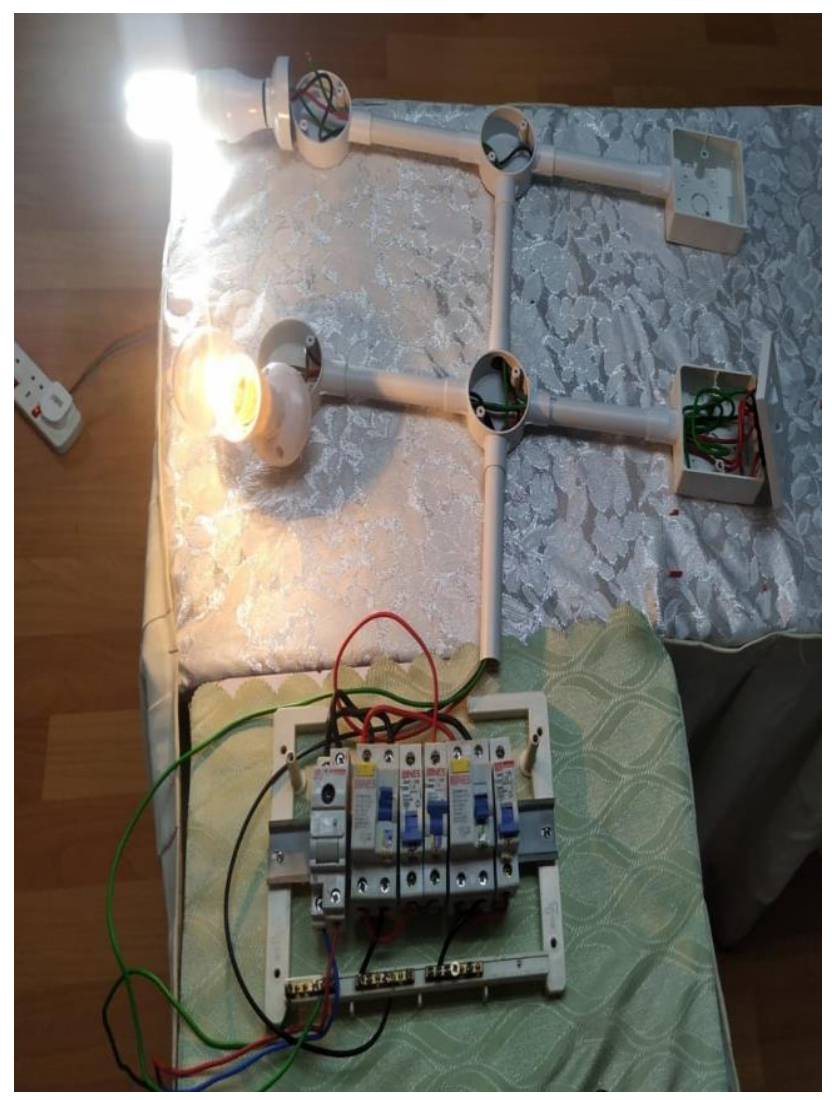

(b)

Fig. 4. (a) Electric Distribution Box connecting to the lighting system through PVC conduit. (b) Install the lighting system, two switches, and the Distribution Box.

\section{ESP8266}

The ESP8266 Wi-Fi board is shown in Figure 5 which requires a micro-USB cable connecting to the computer when uploading the program from Arduino software (IDE). The presetup of ESP8266 is compatible with the Arduino UNO board as shown in Figure 6. Unlike the normal switch, both the neutral line and the live line is required because extra power is needed to operate ESP8266.

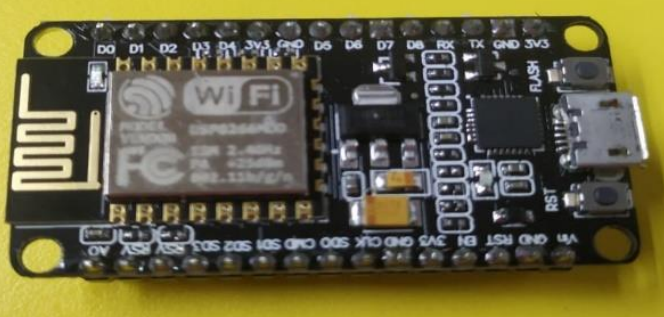

Fig. 5. ESP8266 Wi-Fi board.

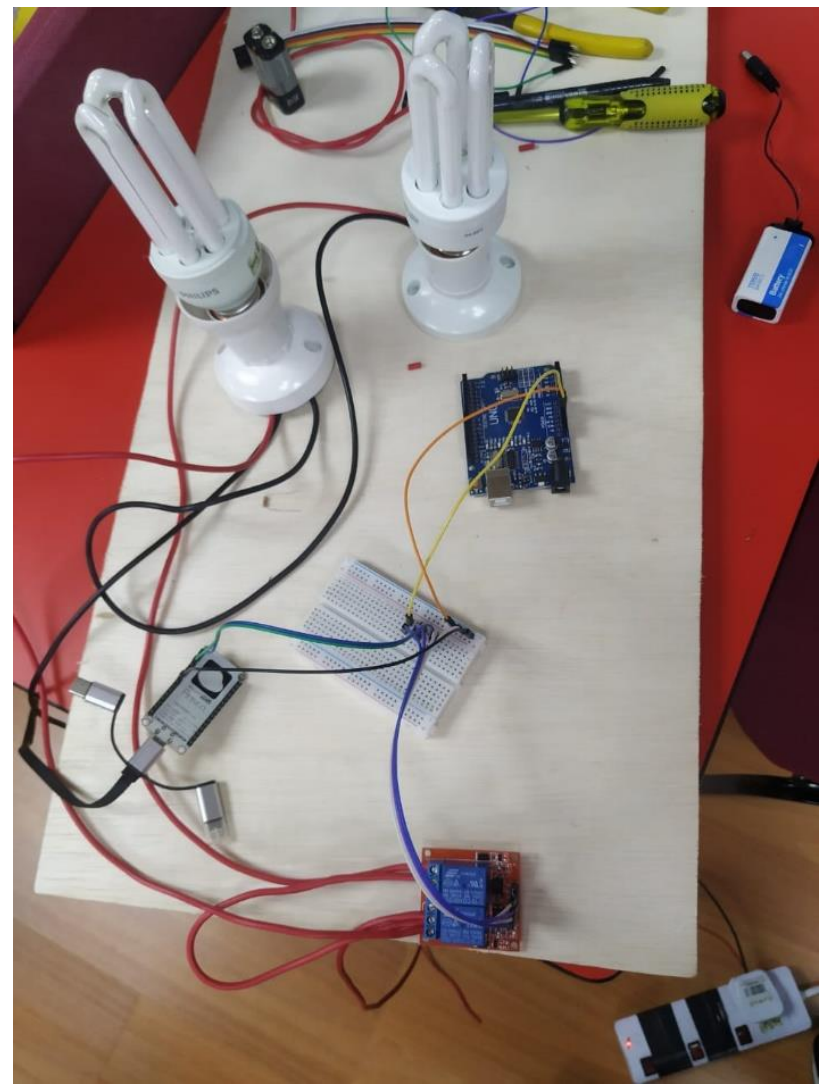

Fig. 6. Pre-setup of ESP8266 Wi-Fi board, Arduino UNO board connected to the lighting system via breadboard and relay circuit.

\section{Coding And ESP8266 Web Server}

In this section, the program is written and uploaded to the ESP8266 Wi-Fi board, function it needed to turn on or turn off the IoT Smart Home Lighting System when the user presses the switch button on the smartphone application that is connecting to a Wi-Fi network.

\section{A. Setup and Loop Function in Arduino Program}

In the Arduino program, there are two necessary functions which are called setup() and loop(). These functions need to be called or declared first; each function usually has a unique name 
$>$ REPLACE THIS LINE WITH YOUR MANUSCRIPT ID NUMBER (DOUBLE-CLICK HERE TO EDIT) <

that allows parts of the computer program to run specific commands. Similarly, we can declare variables before we get into the main part of the program. By giving the name of variables we want, the value is stored into the Arduino's memory to inspect some changes when the variable changes depending on our program instructions. For example, a variable with an int will hold an integer value or whole number without a decimal point. Every statement of code usually ends with a semicolon (;). The setup function will run when the Arduino UNO board is powered on followed by the loop function right after the setup function has been completed.

The loop function check for any incoming user connecting to the Wi-Fi network so that the user can be connected to the proposed Smart Home System. The digital pins are configured to be the lighting system which is the outputs using a function called pinMode(). In addition, we use digitalWrite () as a function to ensure the initial state of our outputs pin 4 and pin 5 are low (off). The state of the output pins digitalWrite () will get from low to high only when the user is turning on the switch button from the smartphone, indicating a voltage is passing through the output pins 4 and 5 or both. The Arduino program will pass the instructions from the (IDE) to ESP8266 Wi-Fi board to do the job by turning on and off the lighting system. Figure 7 shows the setup and loop functions, including the variables and the pins used as outputs for the Smart Home Lighting System.

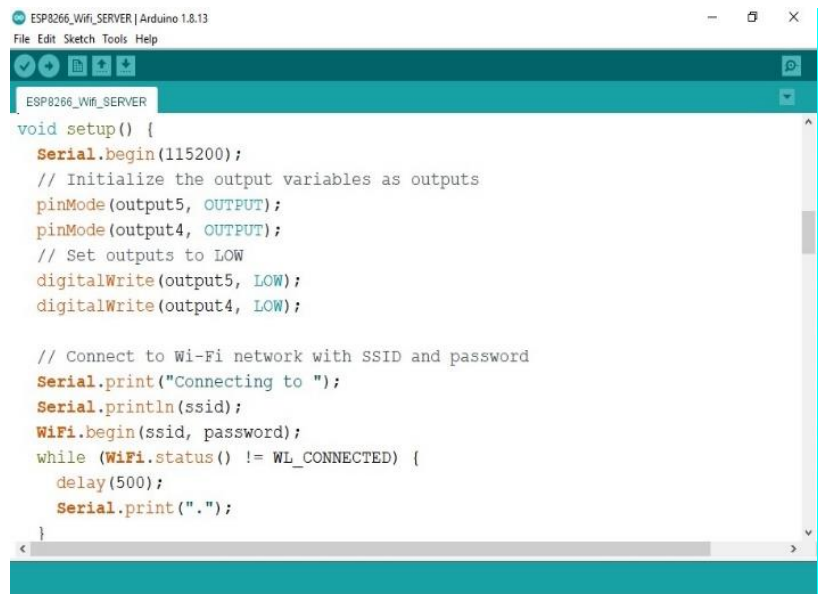

(a)

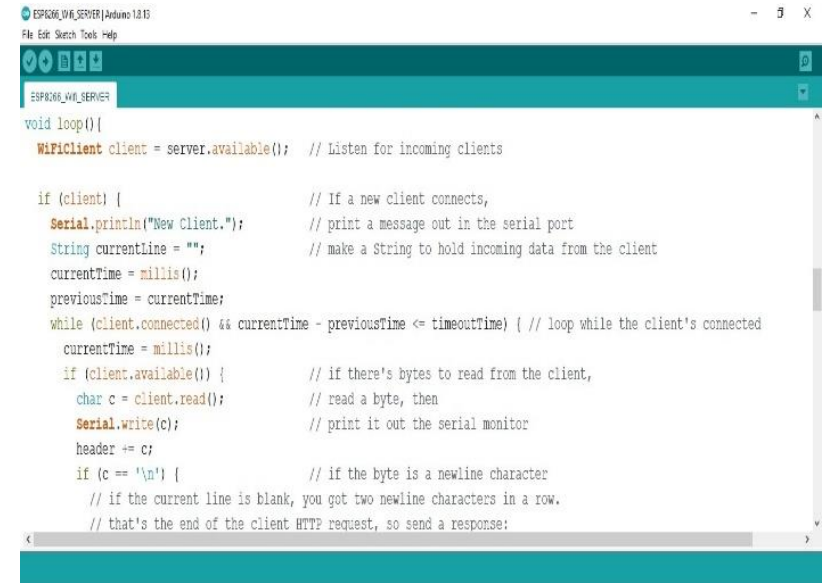

(b)

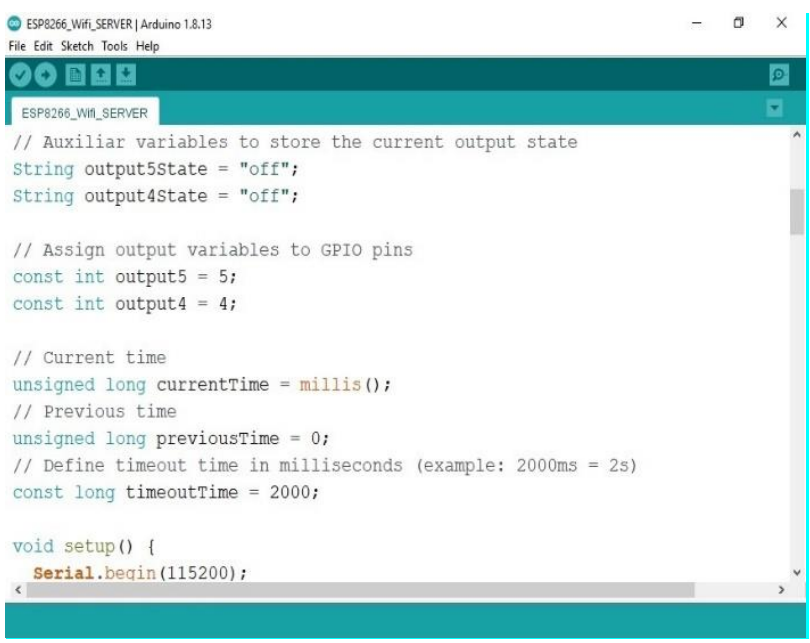

(c)

Fig. 7. (a) Setup function and pinMode function to declare the output pins in Arduino program. (b) Loop function to keep track of new users connecting to the Wi-Fi network. (c) Declare variables as GPIO output at pin 5 and pin 4 .

\section{B. Code for Initial Setup for ESP8266 Web Server}

There are some examples of built-in sketches that can be found in Arduino (IDE). Simply open the blink sketch, by going to File and opening the Examples folder, and then open the Basics folder. Figure 8 shows the continuation of code from the loop function for establishing a connection between the user and the Web Server. It is the initial step to turn on and off the lighting system when the user is connected to the Wi-Fi network. The Web Server design can be creative by using attractive colours, and fonts, to fit the user's preferences. 
$>$ REPLACE THIS LINE WITH YOUR MANUSCRIPT ID NUMBER (DOUBLE-CLICK HERE TO EDIT) <

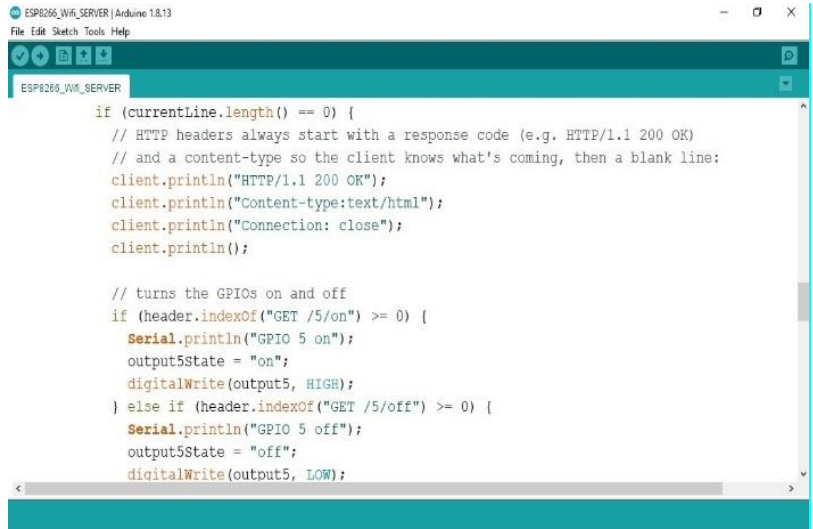

(a)

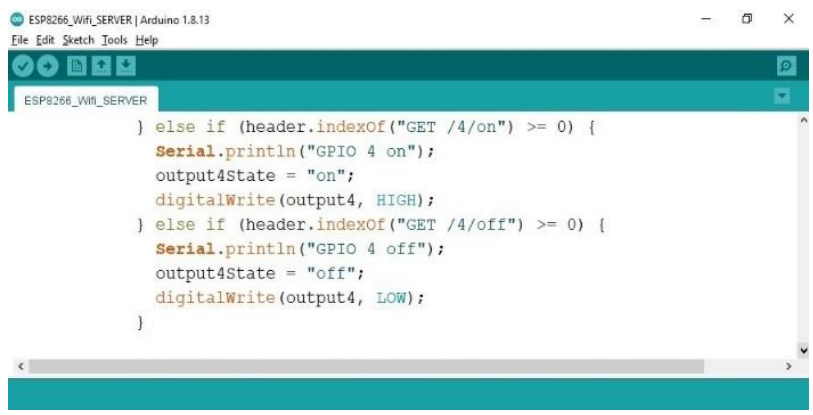

(b)

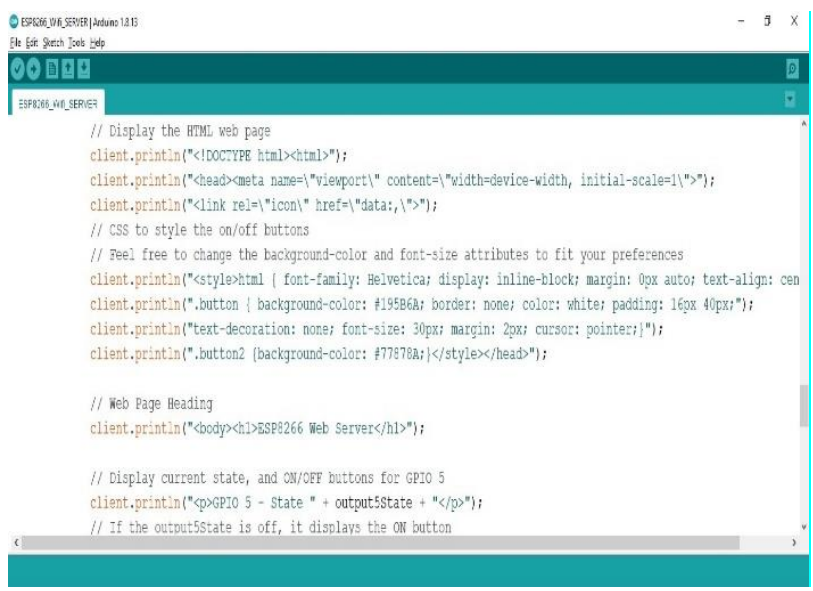

(c)

Fig. 8. (a) Code continuation from the loop function in Arduino program to enable the user to turn on and off the first fluorescent lamp. (b) Continuation from (a) but only enable the user to turn on and off the second fluorescent lamp. (c) Code for setting up the ESP8266 Web Server, showing the user the status of the smart home lighting system in real-time.

\section{Continuation from the Web Server}

The Web Server from the browser app is the User Interface (UI) from the user's smartphone, enabling the authorized user to control the switches or electrical components when accessing the Wi-Fi network. Hence the user can control the fluorescent lamps of the proposed Smart Home Lighting System based on their conveniences. This Web Server is a user-friendly software application, providing the IoT ecosystem such as Smart Home Lighting System for easy user interaction and new experience to interact remotely using smartphones, tablets, and laptops. The continuation of code for the ESP8266 Web Server is shown in Figure 9 which tells the user the state of the lighting system in real-time and changes when the user presses the switch button from the ESP8266 Web Server. Noted that $\langle p\rangle$ is a paragraph, <a href is a link, usually the URL you go to when pressed, which directed the authorized user to the server to turn on or off the Smart Home Lighting System.

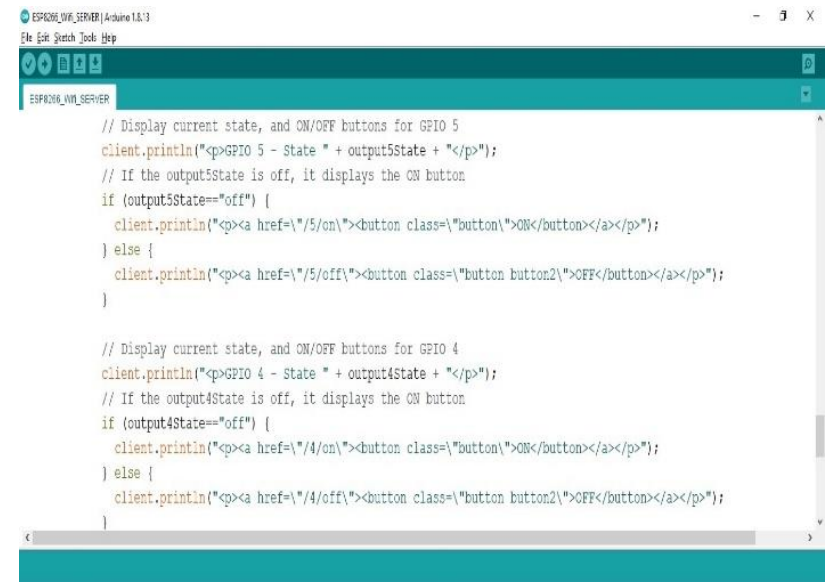

(a)

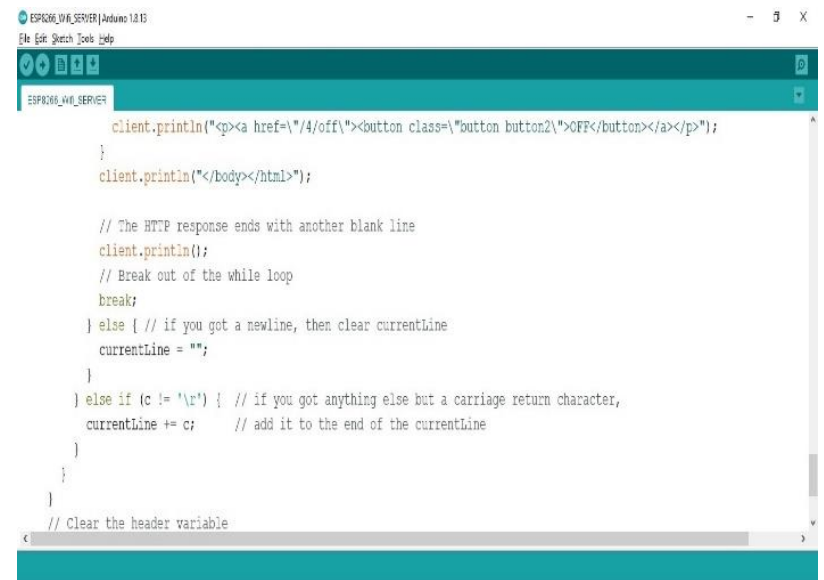

(b) 


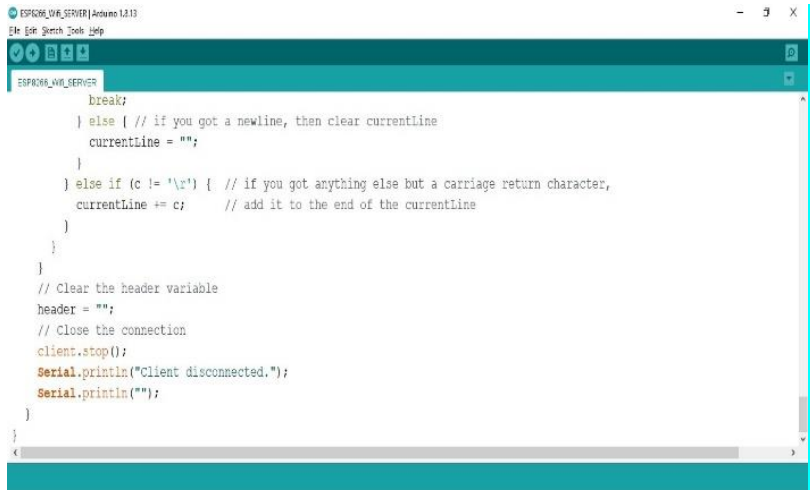

(c)

Fig. 9. (a) Code continuation for the ESP8266 Web Server in Arduino program to enable the user to read the status of the smart home lighting system. (b) Code for breaking away from the while client.connected function. (c) Code for clearing the header variable once the user disconnected from the Wi-Fi network after being used.

The ESP8266 Web Server display on the smartphone is shown in Figure 10, which displays the state of the buttons and waiting for the user to press the switch button to turn on or off the Smart Home Lighting System. The user must be authorized to the Wi-Fi network in order to turn on and off the proposed Smart Home Lighting System. When the user did not respond to the switch for a given time, the program will terminate the user's authority to switch on or off the lighting system unless the user is connected and re-authorized by the Wi-Fi network. The ESP8266 Web Server displays the state of the lighting system in real-time to prove there is synchronization between the Web Server application with the ESP8266Wi-Fi board. After the user exit from the ESP8266 Web Server or is disconnected from the Wi-Fi network, the ESP8266 Web Server will be terminated based on the code written in the Arduino program presented in Figure 9. (c).

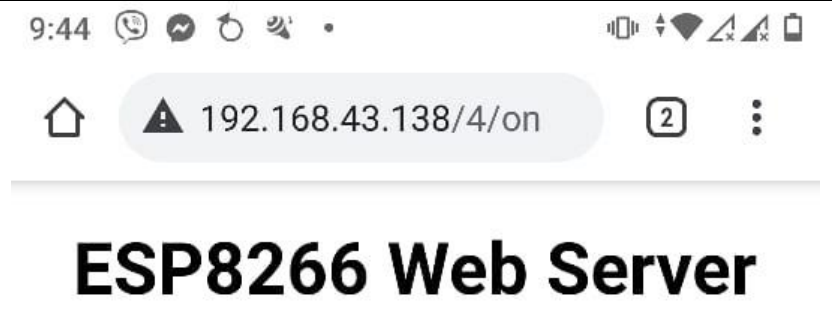

GPIO 5 - State on

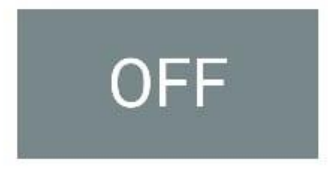

GPIO 4 - State on

OFF

(a) 


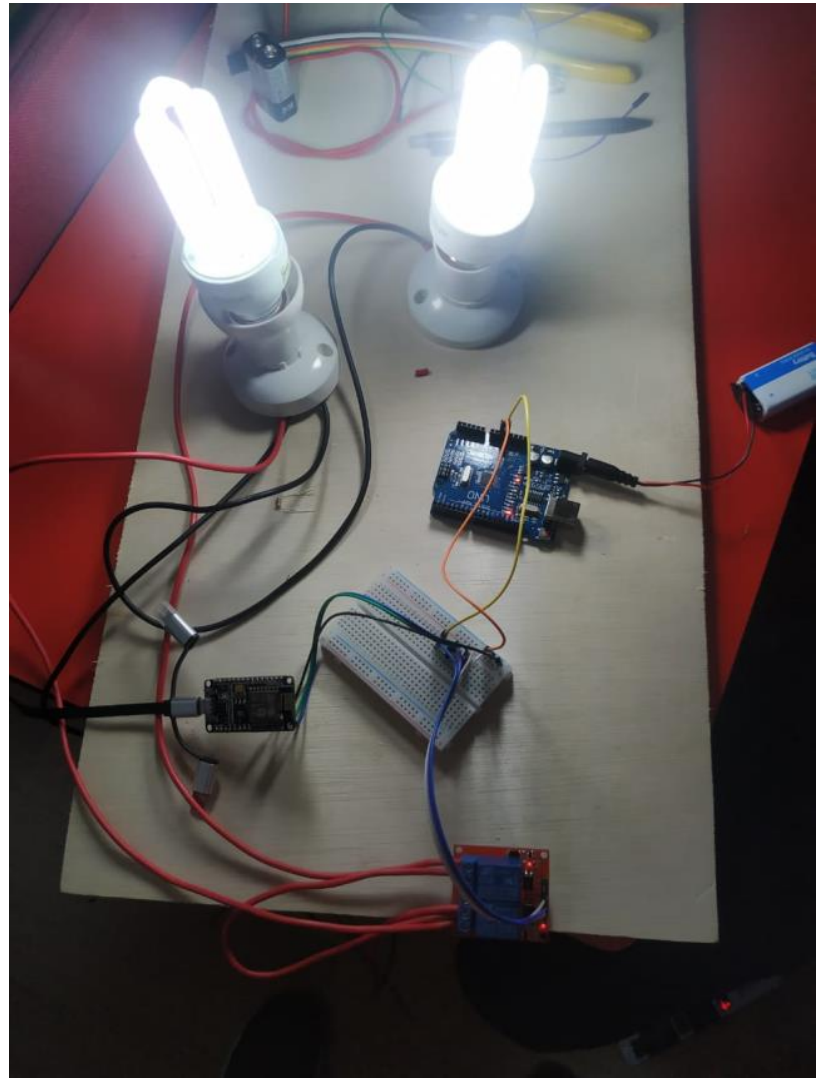

(b)

Fig. 10. (a) ESP8266 Web Server showing both the fluorescent lamps at GPIO 5 and GPIO 4 are turning on. (b) The actual setup of the proposed smart home lighting system after the switch buttons were turned on from the ESP8266 Web Server.

\section{CONCLUSION}

In this paper, a prototype Smart Home Lighting IoT-based System using an Arduino UNO and an ESP8266 board is designed and presented to monitor the home lighting system in real-time. Moreover, the use of ESP8266 provided the features such as improving the user's interaction with connected devices and enhancing the capability of remote controlling the need of a Smart Home environment for example the fluorescent lamps proposed as our lighting system, and Arduino Software IDE Programming is the heart of this project which controls the entire process. The proposed Smart Home Lighting System will become demanding in the future towards the Digital Transformation of IR 4.0 covering from Smart Home to Smart Office, Smart City, and Smart Industrial applications. The contribution of IoT Smart Home technology will eventually solve major problems by supporting aids to the disabled people who walking or moving to a place is a hinder for them, as well as the inconvenience of daily electrical wastage problem, such technology will ease their needs.

\section{RECOMMENDATION AND FUTURE WORKS}

Further works can be done on this prototype system written in Python Programming Language using Raspberry Pi instead of simple C Programming Language. The Raspberry Pi is a single-board computer (SBC) that can be connected to the Internet using Ethernet or Wi-Fi and has up to 40 GPIO pins that can be connected to different sensors for different industrial applications.

\section{ACKNOWLEDGMENT}

The authors wish to appreciate Mr.Rajendran A/L C. Periasamy for his assistance and encouragement throughout the five weeks of the hands-on training process, and financial support by the Malaysian government under the Penjana Scheme Human Resources Development Fund - Gerak Ihsan Gemilang (HRDF - GIG) for conducting this successful training program at CQ-TEC (P. J.) SDN BHD during the midst of COVID-19 pandemic.

\section{REFERENCES}

[1] Joint Radio Company Ltd, "Cutting Through the Hype: 5G and Its Potential Impacts on Electric Utilities," White Paper prepared for the Utilities Technology Council, pp. 7-16, Mar. 2019.

[2] M. Aly, F. Khomh, and S. Yacout, "What Do Practitioners Discuss about IoT and Industry 4.0 Related Technologies? Characterization and Identification of IoT and Industry 4.0 Categories in Stack Overflow Discussions," Internet of Things, vol. 14, p. 100364, 2021.

[3] J Y. N. Lin, S. K. Wang, C. Y. Yang, V. R. L. Shen, T. T. Y. Juang, and W. H. Hung, "Development and verification of a smart remote control system for home appliances," Comput. Electr. Eng., vol. 88, p. 106889 , 2020.

[4] J. Rajasekhar, M. T. Basu, and N. S. S. Sowjanya, "Smart governance of home through IoT," Mater. Today Proc., 2021.

[5] Samsung, "Internet of Things Introducing innumerable opportunities", Samsung, $2020 . \quad$ [Online]. Available: https://images.samsung.com/is/content/samsung/p5/global/business/netwo rks/insights/white-paper/iot-white-paper/global-networks-insight-iotwhitepaper-0.pdf.

[6] O. Elijah, T. A. Rahman, I. Orikumhi, C. Y. Leow, and M. N. Hindia, "An Overview of Internet of Things (IoT) and Data Analytics in Agriculture: Benefits and Challenges," IEEE Internet of Things Journal, vol. 5, no. 5, pp. 3758-3773, Oct 2018, doi: 10.1109/jiot.2018.2844296.

[7] NTT DOCOMO, INC. "5G Evolution and 6G," White paper, pp. 2-3 Jan 2020.

[8] P. U. Okorie, A. A. Ibraim, and D. Auwal, "Design and Implementation of an Arduino Based Smart Home," HORA 2020 - 2nd Int. Congr. HumanComputer Interact. Optim. Robot. Appl. Proc., 2020

[9] Arduino. Arduino IDE 1.8.16. [Online] Available: https://www.arduino.cc/en/Main/Software.

[10]Arduino. (2018). Getting Started with Arduino UNO. [Online] Available: https://www.arduino.cc/en/Guide/ArduinoUno.

[11]Arduino. (2018). Introduction to Arduino Uno. [Online] Available: https://www.theengineeringprojects.com/2018/06/introduction-toarduino-uno.html.

[12]Crux Of Electrical Engineering. [Crux of EE]. (2020, July 28). Akta Bekalan Elektrik 1990 dan Peraturan Elektrik 1994 Malaysia Berkaitan $\begin{array}{lll}\text { Keselamatan Elektrik. } & \text { [Video]. } & \text { YouTube. }\end{array}$ https://www.youtube.com/watch?v=kXFx3IdRatg. 


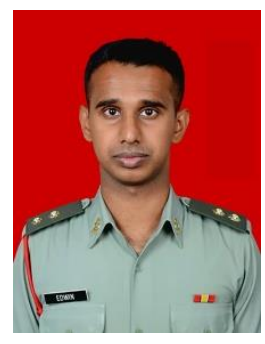

Edwin Nair Jannatheran received B.S in Physics, Electronic and Instrumentation from Universiti Malaysia Terengganu, Malaysia in 2012. He is currently pursuing MPhil in Electrical Engineering at Universiti Teknologi Malaysia. His major field of studies includes RF and wireless communications as well as drones.

$\mathrm{He}$ is currently working with Malaysia Army Signal Directorate and focusing on Tactical Radio ranging from $\mathrm{HF}$ to Microwaves tactical equipment. His job scope involves in modern warfare technologies includes battlefield management system, RF analysis, and propagation studies on the battlefield focusing on V/UHF tactical application.

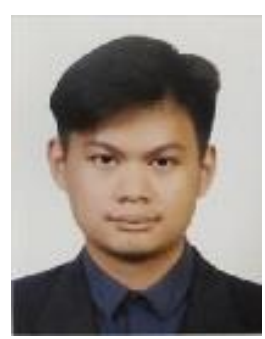

Vincent Yong Kai Loung received the B.Eng. degree in electrical and communication engineering from Universiti Teknologi Brunei in 2016, the M.S. degree in electronic and telecommunication engineering from Universiti Teknologi Malaysia, Skudai, Malaysia, in 2018.

He worked at Huawei Technologies (M) Sdn. Bhd from 2018 to 2019 as a Product Configuration Engineer. He is currently pursuing his Ph.D. degree in electrical engineering and has also been 1 year with the Wireless Communication Centre (WCC) Universiti Teknologi Malaysia, Kuala Lumpur as a Graduate Research Assistant from 2020 till 2021. His research interests include wireless network technologies, antennas design, and propagation study with emphasis on $5 \mathrm{G}$ applications.

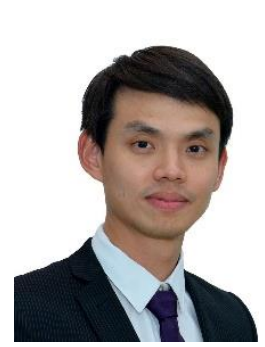

Chee Yen (Bruce) Leow received the B.Eng. degree in computer engineering from Universiti Teknologi Malaysia (UTM) in 2007 and the Ph.D. degree from Imperial College London in 2011. Since July 2007, he has been an Academic Staff with the School of Electrical Engineering, Faculty of Engineering, UTM, where he is currently an Associate Professor. He is also a Research Fellow with the UTM Wireless Communication Centre and the UTM-Ericsson Innovation Centre for 5G. His research interests include non-orthogonal multiple access, UAV communication, MIMO, hybrid beamforming, physical layer security, wireless power transfer and prototype development using software defined radio, for $5 \mathrm{G}$ and the IoT applications. 